\title{
(RE) PENSAR A FORMAÇÃo DE PROFESSORES PELO CAMINHO DA COOPERAÇÃO
}

\author{
Jose Wnilson Figueiredo ${ }^{1}$ \\ Adriana Salete Loss ${ }^{2}$ \\ Daniela Ghisleni Figueiredo ${ }^{3}$
}

\section{RESUMO}

A partir de uma experiência pedagógica, o presente artigo pretende estabelecer uma interlocução a respeito da implantação de uma formação de professores, por meio de uma metodologia de cunho coletivo, ancorada em uma razão solidária, sustentada na cooperação em oposição à hegemonia da razão neoliberal individualista, vigente na atualidade. Para tanto, nos amparamos nas categorias da ética da alteridade e do diálogo como fundamentos para a criação e recriação de práticas políticas e pedagógicas com vistas à abertura de possíveis caminhos para a constituição de um professor disponível ao outro e ao coletivo (escola e sociedade), bem como do surgimento de uma educação pautada pela cooperação e que, em última instância, contribua para a edificação de uma civilização comunitária. A percepção é que a efetivação do sugerido é essencial para uma formação docente libertária.

\footnotetext{
${ }^{1}$ Doutor Em Educacão nas Ciências pela Universidade Regional do Noroeste do Estado do Rio Grande do Sul (UNIJUI).Pós-doutor em ensino de Ciências e Matemática pela Universidade Federal do Rio Grande do Norte (UFRN). Professor do curso de licenciatura em Matemática pelo Instituto Federal Catarinense - Campus Concórdia. ORCID: http://orcid.org/0000-0002-2461-8724. Email: jose.figueiredo@ifc.edu.br

${ }^{2}$ Doutora em Educação pela Pontifícia Universidade Católica do Rio Grande do Sul (PUC RS).Pós-doutora em Educação pelo Instituto de Educação da Universidade de Lisboa. Professora do Programa de Mestrado Interdisciplinar de Ciências Humanas da Universidade Federal da Fronteira Sul (UFFS).ORCID: http://orcid.org/0000-0001-5576-0929.Email: adri.loss@uffs.edu.br

3 Graduada em Direito pela Universidade do Contestado.Acadêmica do Mestrado Interdisciplinar em Ciências Humanas da Universidade Federal da Fronteira Sul. ORCID: http://orcid.org/0000-0002-7061-7247. Email: dany_ghisleni@hotmail.com
} 
Palavras-chave: Formação de Professores. Cooperação. Razão Neoliberal.

\section{(RE) THINKING ABOUT TEACHER TRAINING ON THE PATH OF COOPERATION}

\section{ABSTRACT}

Based on a pedagogical experience, this article intends to establish an interlocution regarding the implementation of a teacher training, through a collective methodology, anchored in a solidary reason, sustained in cooperation in opposition to the hegemony of the neoliberal individualist reason, currently in force. To this end, we rely on the categories of the ethics of alterity and dialogue as foundations for the creation and re-creation of political and pedagogical practices with a view to opening up possible paths for the constitution of a teacher available to the other and to the collective (school and society), as well as the emergence of an education based on cooperation and ultimately contributing to the building of a community civilization. The perception is that the implementation of what is suggested is essential for a libertarian teacher training.

Keywords: Teacher Training. Cooperation. Neoliberal Reason.

\section{(RE)PENSAR LA FORMACIÓN DEL PROFESORADO A TRAVÉS DEL CAMINO DE LA COOPERACIÓN}

\section{RESUMEN}

A partir de una experiencia pedagógica, el presente artículo pretende establecer una interlocución acerca de la implantación de una formación de profesores, por medio de una metodología de cuño colectivo, anclada en una razón solidaria, sostenida en la cooperación en oposición a la hegemonía de la razón neoliberal individualista, vigente en la actualidad. Para ello, nos amparamos en las categorías de la ética de la alteridad y del diálogo como fundamentos para la creación y recreación de prácticas políticas y pedagógicas con 
miradas a la apertura de posibles caminos para la constitución de un profesor disponible al otro y al colectivo (escuela y sociedad), así como del surgimiento de una educación pautada por la cooperación y que, en última instancia, contribuya a la edificación de una civilización comunitaria. La percepción es que la efectividad de lo sugerido es esencial para una formación docente libertaria.

Palabras Clave: Formación de Profesores. Cooperación. Razón Neoliberal.

\section{INTRODUÇÃO}

O texto traz uma análise a respeito dos limites e das possibilidades da constituição de um ensino e de uma aprendizagem, no processo de formação inicial e continuada de docentes, a partir de um agir cooperativo entre educandos (as) e educadores(as), tendo como elo condutor o processo de comunicação que se almeja implementar, nos espaços das escolas e em outros ambientes pedagógicos da sociedade, de uma educação sustentada em valores fundamentados pelo diálogo e pela alteridade.

Para tanto, faz-se necessário uma reflexão acerca das práticas educativas da contemporaneidade, por meio de uma metodologia participativa, consubstanciada na tríade ver, julgar e agir, a qual se baseia na observação e na atuação crítica frente aos problemas enfrentados pelos sujeitos do "quefazer' pedagógico e político.

Desse modo, inicialmente faremos um retrato - inacabado e inconcluso - acerca da situação que a humanidade atravessa no cenário atual da contemporaneidade, em especial nos campos da política, da educação e da economia, os quais influenciam as relações humanas nos subsistemas e sistemas da sociedade como um todo, trazendo consequências para o viver dos seres humanos em suas relações com os outros, que se dá em situações históricas, sociais e culturais.

Essas situações revelam as crenças e as compreensões que esses seres humanos têm a respeito da vida, de um modo geral, e da educação de maneira particular, ou seja, essas crenças e compreensões têm suas gêneses em contextos históricos e culturais, 
que revelam traços importantes para que - a partir de dados e situações concretas desses contextos - julguem estes para que, em diálogo, pesquisadores-pesquisandos e pesquisandos-pesquisadores possam agir criticamente, em comunhão, com vistas à transformação social.

As concepções e as análises do quefazer político e pedagógico, que estão imbrincadas na ação humana, são partes conectadas das experiências do dia a dia das vivências dos seres humanos, isto é, daquilo que, frequentemente, nominamos como mundo real.

Numa perspectiva crítica, o processo de ensinar e aprender se constitui pela interlocução do pensamento e do fazer coletivo a partir do entendimento desse mundo pela problematização dos setores, que constituem o mundo social.

Entendemos o coletivo como pessoas que atuam e agem, no e com o mundo, partilhando os com os outros e toda comunidade da vida numa perspectiva dialógica e crítica, a qual se fundamenta numa prática e numa pesquisa apoiada na intercomunicação que interliga os diferentes saberes (saberes populares e saberes da ciência ). Nessa direção, investigar uma determinada situação que se coloca como problema é:

puxar os cordões que ligam entre si as práticas de um mesmo campo empírico em sua continuidade histórica e, ao mesmo compasso, os entrelaçam com os cordões que vinculam e conduzem os entendimentos que de tais práticas se alcançam no campo teórico. (MARQUES, 1998, p. 102)

Portanto, interliguemos os fios que produzem o cenário atual do mundo contemporâneo.

No cenário vigente da realidade social do mundo vigente, estamos submetidos a um paradigma hegemônico produzido pela força da razão neoliberal que domina e impõe um modo de vida associado e guiado pelo mercado como um fator que ordena e condiciona as relações sociais, as quais se estruturam pela competitividade, pelo individualismo, pela ganância e pela indiferença ao outro. 
Dessa feita, o encontro entre os seres humanos - na maioria das vezes - são constituídos por atitudes verticais em que um dos polos desses encontros reifica o outro polo, o qual é oprimido e subjugado. O que vale, nesse caso, é a exploração da maioria em favor de uma minoria. Como consequência dessa exploração, essa maioria usufrui das benesses do capital. O ser humano é moldado para ser um gestor do seu próprio destino pessoal a partir de uma visão fundamentada na ação racional com vistas à obtenção da maximização do lucro com o mínimo de dispêndio.

Assim sendo, a razão neoliberal enfraquece e até certo ponto dissolve os laços da participação em torno de um projeto comunitário e democrático, já que cada um dos indivíduos são educados para serem competidores eficazes em detrimento da formação de indivíduos que atuem em prol da cooperação da coletividade. Nessa direção, essa razão acaba por estabelecer a necropolítica em que os poderosos decidem quem vai viver e quem vai morrer. (MBEMBE, 2018).

Logo, essa razão acaba produzindo um quadro social contrário ao de uma convivência amistosa estabelecida em torno do diálogo e da alteridade. Daí, decorre que se estabelece um ambiente contrário ao exercício de ações político-pedagógicas organizadas pela ética do ser mais com o outro, já que predomina a ética do mercado forjada no culto ao individualismo e do consumismo, ou seja, numa ética que apregoa que o indivíduo deve guiar sua existência por uma lógica empresarial de si mesmo em que o lucro é o fim a ser buscado em detrimento da partilha comunitária.

Com resultado dessa ética, a educação é estruturada sob a égide de um pensamento que apregoa que o ser humano deve pautar suas ações pelo estabelecimento de hábitos forjados em atitudes do tipo eu-isso, as quais são organizadas em torno da não abertura ao outro e ao mundo, ou seja, um dos polos do relacionamento - o eu - é considerado sujeito enquanto o outro polo, o tu, é considerado como um isso (um objeto).(BUBER, 2001).

Dessa maneira, ocorre uma acentuada desumanização devido ao fato de que essa ética de mercado neoliberal promove um centramento do ser humano em si mesmo em detrimento da formação humana coordenada em função de um agir comunitário, 
em que as pessoas são educadas em função da criação e recriação do conhecimento fundada na solidariedade. Logo, essa ética gera condições objetivas e subjetivas para a emersão de um sujeito voltado para si e, consequentemente, dominado pela lógica empresarial, a qual:

produz o sujeito de que necessita ordenando os meios de governá-lo para que ele se conduza realmente como uma entidade em competição e que, por isso, deve maximizar seus resultados expondo-se a riscos e fracassos. "Empresa" é também o nome que se deve dar ao governo de si na era neoliberal. (DARDOT; LAVAL, 2016, p. 328).

Como decorrência dessa lógica empresarial, o mundo da vida e das instituições sociais, incluindo as escolas, sofrem uma degradação do ponto de vista da realização de uma humanidade plena, já que a ação coletiva é quase deixada de lado na esfera social. O que se ver é que cada vez mais a ética do mercado promove e produz a destituição da cidadania, da democracia e da política como um campo que cria e recria condições para que emerjam práticas promotoras da solidariedade entre as pessoas e entre as organizações sociais. A política é subjugada ao econômico, que induz práticas que deixam $\mathrm{o}$ indivíduo à própria sorte, sem auxílio do Estado.

Em uma posição divergente aos preceitos da ética de mercado competitiva. Advogamos em favor de uma formação pedagógica moldada em uma epistemologia que conceba o ser humano como um ser que se dirige ao outro a partir de valores que consagram a ética do ser mais forjada em um agir cooperativo em oposição ao ter mais individualista, ou seja, que : "a competição ceda lugar à cooperação solidária, à partilha, à complementaridade e a solidariedade". (ARRUDA,2003, p.29).Enfim, que a formação humana seja pensada a priori através da cooperação. 


\section{FUNDAMENTOS DA FORMAÇÃO DOCENTE COM BASE NA COOPERAÇÃO}

De maneira contrária às orientações da lógica capitalística, podemos (re) pensar a formação humana, de modo geral, e a formação de educadores, de maneira particular, por intermédio de práticas consubstanciadas na, com e pela cooperação entre os atores sociais do fazer político e pedagógico, os quais devem atuar em torno da consecução de relações sustentadas pelas categorias do diálogo e da alteridade com vistas à mudança da realidade social dos espaços das escolas, bem como do conjunto da sociedade.

Nesse sentido, se faz necessário que a formação de docentes seja estruturada em concepções que possibilitem, na prática, o emprego de metodologias coletivas fundamentadas em relações fundadas na reciprocidade e na intertroca de saberes em substituição às metodologias positivistas, caracterizadas pelo egocentrismo e pela ausência de horizontalidade na comunicação dos atores do processo de ensino e aprendizagem.

A mudança dessa realidade necessariamente ocorre e ocorrerá por meio da participação conjunta, sob o signo da igualdade, ou seja, a formação docente deve e pode ser (re)pensada a partir de uma epistemologia coletiva em que os participantes dos processos de ensino e aprendizagem narrem os seus saberes a respeito de um determinado tema ou conteúdo, através do refletir e do agir cooperativo, que se dá de modo circular, cujo ponto de partida e de chegada é a adoção de um processo impregnado pelo princípio dialógico e pelo reconhecimento ao outro.

Esse processo acontece pela comunhão entre os sujeitos - que prevalece sobre o individualismo hegemônico -, a qual se notabiliza pela partilha dos saberes por meio de uma atitude em que um dos polos da relação (o eu) vai ao encontro do outro polo dessa relação (o tu) por meio de um movimento de responsabilidade e de respeito à alteridade, isto é, através de práticas baseadas numa comunicação forjada na amorosidade, em que a totalização do outro (o educando) pelo o educador dar lugar à assunção de uma educação como prática de cooperação. 
Neste tipo de educação, todos os sujeitos ensinam e aprendem ao mesmo tempo dentro de um fazer e refazer pedagógico e político embebidos numa razão solidária, a qual ocorre: "por um movimento de personalização que se contrapõe ao movimento de despersonalização da razão neoliberal." (FIGUEIREDO; FRANTZ, 2018, p.46).

Esse movimento irrompe pela afirmação dos seres humanos como protagonistas da ação social, que se estabelece por meio de encontros genuínos com base na vivência do reino do inter-humano, o qual se constitui pela presença e pelo engajamento crítico com vistas à produção de práticas pedagógicas e políticas ancoradas e estruturadas, sob a égide de valores que apregoam o ser humano como um ser de cuidado - que tem como atributos: a reciprocidade, a disponibilidade, a compreensão, a abertura ao outro e ao mundo em substituição a aspectos que afirmam o ser humano como um ser voltado para si, que tem como características: o anti-diálogo, o egoísmo, e a não abertura ao outro e ao mundo.

Essas pessoas se constituem a partir da intercomunicação e da ética da alteridade como fundamento filosófico primeiro das suas ações, a qual é consignada pela atividade em direção ao outro consubstanciada pelo encontro face a face estruturado pela responsabilidade a esse outro - que é totalizado pela hegemonia da concepção centrada na autonomia do ser da racionalidade do ocidente -, a qual se configura pela não redução daquele ao mesmo. (LÉVINAS, 2000).

Essa transformação prescinde a priori dessa ética, que se efetiva, na prática, por meio uma educação em que o outro é respeitado e acolhido no seu modo de ser como pessoa numa perspectiva em que o ensinar e o aprender tem como ponto de partida à busca da libertação do educador e dos educandos em colaboração, que se dá - na prática - por atividades impregnadas por meio do fazer que:

interpela para que as instituições sociais, enquanto expressões organizativas de uma sociedade humana, orientem-se a partir de uma perspectiva antropológica sensível e aberta para acolher o outro - hospitalidade que anuncia o significado da própria 
liberdade que se faz acolhida (DALLA ROSA, 2010, p.85).

Daí decorre que a formação dos educandos, em especial dos futuros docentes, é realizada dentro de um espírito em que o eu (professor formador) trabalho os conteúdos numa perspectiva da ação-reflexão-ação em comunhão com os educandos, os quais são acolhidos por esse professor numa perspectiva da cooperação.

Neste trabalho, os conteúdos são apresentados por esse professor a pequenos grupos da turma, que são refletidos e compreendidos nestes grupos para que - em seguida - sejam comunicados a todos os componentes dessa turma, os quais junto com o professor fazem a elaboração e a síntese final do que foi ensinado e aprendido ao final dos encontros de ensino e de aprendizagem.

Nesse sentido, o agir dos educandos e o agir do educador são pautados pelo diálogo genuíno vivido a partir de uma atmosfera de congraçamento e aceitação mútuas entre esses, os quais atuam em colaboração e - como consequência - sem pedantismo na produção dos conhecimentos e na constituição do ser de cada participante desse diálogo, que irrompe a partir do dar, do receber e do retribuir comunitário dos gestos, das escritas e das falas de todos sujeitos do processo de ensino e de aprendizagem. A respeito do diálogo genuíno, verifica-se que:

Ao fundar-se no amor, na humildade, na fé dos homens, o diálogo se faz numa relação horizontal, em que a confiança de um polo no outro é consequência óbvia. Seria uma contradição se, amoroso, humilde e cheio de fé, o diálogo não provocasse esse clima de confiança entre seus sujeitos. Por isto inexiste essa concepção na concepção "bancária" de educação. (FREIRE, 2005, p.113).

Esse processo, que é estruturado pelo movimento dialógico, emerge de uma tomada de posição e de uma prática pedagógica orientada por métodos capazes de favorecer e instigar a colaboração 
dos educandos e educadores em prol da produção coletiva do conhecimento, que se configura por um processo metodológico que:

pressupõe a comunhão entre os seres humanos, que acontece, conforme Berdiaeff (1935), no amor como encontro do eu e do tu, isto é, a partir da realização da utopia como uma humanização concreta, no sentido cunhado por Bloch (2005), que se configura historicamente pela radicalização crítica do diálogo entre os seres humanos em que cada um deles atua em consonância com o outro, respeitando a opinião deste e - ao respeitar esta opinião - estabelece uma comunicação que não sufoca e não exclui esse outro. (FIGUEIREDO ; FRANTZ, 2018, p.46).

Nessa direção, essa comunicação forjada na cooperação, deve proporcionar a transformação do mundo das escolas e da sociedade, cuja política e a economia devem estar a serviço da produção de novas subjetividades para que atuem numa conjugação de forças em prol da emersão de uma aliança, nos níveis local e global, com vistas ao surgimento de uma revolução personalista comunitária ancorada num fazer e refazer cotidiano de valorização da vida em sua plenitude, tendo como ponto fulcral a dignidade do ser como pessoa, que se constitui na e com a comunidade e esta como um congraçamento de pessoas, que interagem uma com as outras em um horizonte estruturado por vivências sustentadas pelo amor. (MOUNIER, 1961, 2004).

A respeito desse processo civilizatório, proposto por Mounier, que parte da ideia de uma revolução comunitária que faça a mudança dessa razão, em que o amor vai se constituir-se como unidade na comunidade:

O fundamento da vida humana, como uma forma própria de vida social, é a aceitação do outro na convivência comigo. O elo de sentido desse fundamento é a cooperação. O princípio gerador da cooperação é a emoção e a emoção fundadora das interações humanas é o amor. (BRANDÃO, 2005, p.68). 
Decorre daí que (re)pensar a formação de professores com base no valor da cooperação é imprescindível e urgente nos dias atuais, em que vivenciamos - nestes dias - a hegemonia da formação docente consignada por uma teoria antidialógica, individualista e por conseguinte vertical nos espaços escolares do mundo. Então, é de enorme relevância pautarmos nossas ações pelo agir cooperativo, pois esse agir faz parte como algo constitutivo do ser humano como um ser histórico, social e cultural, ou seja, desde tenra idade, a cooperação é inerente à essência do desenvolvimento dos indivíduos tanto no estabelecimento das sociabilidades primárias, na família, e das sociabilidades secundárias estabelecidas nas instituições da sociedade civil. A esse respeito, Tomassélo diz que os seres humanos:

\begin{abstract}
A partir do primeiro ano - quando começam caminhar e falar e vão-se transformando em seres culturais -, as crianças já mostram inclinação a cooperar e fazer-se úteis em muitas situações, ainda que não em todas. Além disso, não aprendem essa atitude dos adultos: é algo que lhes nasce. (TOMASSÉLO,2010, p.24).
\end{abstract}

Desse modo, por essência, somos seres programados para cooperar com os outros por meio de relações perpassadas por um ensinar e um aprender calcado na ampliação de ações orientadas por uma ética "carregada" de intenções, conversas e gestos fundados na colaboração de cada ser humano com o outro com vistas ao surgimento de comunidades de aprendizagens estabelecidas, sob o signo da alteridade e do diálogo em oposição à ética do mercado baseada no culto ao individualismo e ao lucro

\title{
NARRATIVA CRÍTICA DO PROCESSO DE FORMAÇÃO DE PROFESSORES COMO UM FAZER COLETIVO
}

As práticas pedagógicas ensejadas na disciplina de Seminários avançados: formação de professores, no curso de pós-graduação em ensino de Ciências e Matemática da Universidade Federal do Rio Grande do Norte, se configuraram como momentos de reflexãoação-reflexão sobre o fazer pedagógico numa perspectiva crítica em 
torno das categorias do diálogo e da alteridade vividas, durante as aulas, por meio de momentos e situações em que o reconhecimento às diversidades de pensamento dos discentes e dos docente foram acolhidas e respeitadas dentro de uma atmosfera da cooperação, a qual foi consubstanciada a partir da adoção de uma formação consubstanciada por uma razão solidária oposta à racionalidade técnica instrumental vigente na atualidade

Nesse sentido, a criação e a recriação do conhecimento na referida disciplina foram realizadas numa lógica perpetrada por uma filosofia da educação, cujo ponto de partida e de chegada foi a adoção de uma ética em favor da assunção do ser humano como uma pessoa aberta ao outro e ao mundo em oposição ao individualismo presente na racionalidade técnica, que prega e exerce, nos espaços pedagógicos, um fazer estruturado em uma teoria e prática antidialógica, que vislumbra a formação docente e das pessoas por intermédio de ações pautadas em um viver calcado, como Freire (2005) sinalizou, em uma transmissão vertical dos conhecimentos e consequentemente na opressão exercidas pelos que detém o poder.

$\mathrm{Na}$ contramão desse tipo de Pedagogia, o professor da disciplina de seminários avançados, desde o primeiro encontro, partiu do conhecimento dos discentes para a elaboração dos conhecimentos produzidos no contexto da sala de aula numa perspectiva apoiada na diversidade de vozes presentes no discursos desses discentes.

Para tanto, o professor utilizou - em conjunto com os educandos - de um arcabouço narrativo com vistas à constituição de uma formação docente abarcada na ideia de que o professor e os educandos são coprodutores do conhecimento por intermédio da instituição de uma rede de relações entre os sujeitos do processo de ensino e de aprendizagem, as quais se estruturavam nas e pelas narrativas - orais e escritas - construídas semanalmente, por intermédio dos relatos - via organização das memórias -, as quais retratavam a caminhada pedagógica desses sujeitos.

Essas narrativas foram feitas num horizonte voltado para o entendimento da realidade em que a palavra, os gestos e as ações eram partilhados por todos os componentes do processo educativo de maneira coletiva, cuja finalidade primeira era a garantia da 
participação equitativa de todos num caminhar aberto ao princípio dialógico, a liberdade e a alteridade.

Nesse caminhar formativo da turma e do docente, a preocupação preponderante e central era vislumbrar e permitir que as "memórias" sejam vistas e erigidas como estruturas importantes para a consecução de uma prática educativa transformadora entrelaçadas pelos elementos culturais, históricos e sociais -, cuja ideia-força proposta é a de possibilitar que emerja a resposta de dois elementos essenciais da narrativa das práticas educativas, como Labov (1972) explicitou: o que ocorreu? Por que vale a pena narrar?,

Essas perguntas feitas por Labov, na nossa visão, corresponde a um processo político e pedagógico de ler a realidade do processo formativo em movimento para em seguida julgar o que aconteceu com vistas a uma tomada de decisão como um agir imbricado num processo de formação docente, guiado por métodos que incorporam a participação coletividade como elemento fundante para a construção de um agir consignado numa educação comprometida com a mudança social.

Voltando a essas perguntas, verificamos que a interlocução entre a descrição do que ocorreu e do que vale a pena narrar, nas aulas da disciplina, foram fundamentos importantes para um fazer docente comprometido com a arte de escrever a história das práticas pedagógicas de todos em sintonia com o exercício de uma pedagogia crítica, a qual se ancora num trabalho emancipatório mediado pelo diálogo crítico e verdadeiro com vistas à transformação das pessoas envolvidas no fazer pedagógico e político.

Esse fazer se realizou pela reflexão sobre as práticas docentes concomitante com as ações sobre estas práticas e que, posteriormente, houve novamente um movimento de reflexão sobre estas práticas referidas, constituindo-se por conseguinte em atividades problematizadoras acerca dos temas dialogados e analisados na sala de aula

Essas atividades aconteciam em várias etapas: em primeiro lugar, em todas as aulas, por meio da coordenação do professor da disciplina, que - no início de cada aula - solicitava a leitura das memórias da aula anterior por dois componentes da turma. Havia um engajamento de todos os participantes com o que ocorreu nessa aula 
anterior concomitante com um planejamento coletivo do trabalho pedagógico e político a ser realizado na aula que estava para acontecer.

Em seguida a esse planejamento, as aulas se desenrolavam quase sempre - em três situações didáticas estruturadas numa dinâmica em que o conhecimento era aprendido e ao mesmo tempo partilhado sob a perspectiva de uma teoria da aprendizagem que apontava para uma perspectiva prática da construção coletiva desse conhecimento.

Nessa perspectiva, a turma era dividida pelo professor em grupos em que os componentes de cada grupo dialogavam entre si e com o professor sobre o tema em pauta e em seguida faziam uma síntese representativa do grupo. Depois, em outro momento, todos os grupos reuniam e relatavam coletivamente essas conclusões provisórias acerca do tema em questão para toda a comunidade de aprendizagem. Posteriormente, no final da aula, era feita a síntese final do que seria aprofundado a respeito desse tema com vistas à elaboração de uma reflexão e uma ação, que possibilitasse a todos um maior entendimento acerca do que estava sendo estudado a partir da ideia da mudança social.

Esta mudança foi abarcada por um trabalho, que é constituído pela comunicação intersubjetiva, que se dá pela doação, pelo recebimento e pela retribuição dos conhecimentos de cada um com vistas à formação de um coletivo representativo da diversidade de conhecimentos, que se constitui pelo encontro das individualidades, que partilham entre si procedimentos e habilidades - que envolvem a participação efetiva da turma, como se evidencia pelo relato a seguir:

Depois da saudação inicial do professor da disciplina, o mesmo pediu para que um dos educandos fizesse a leitura da memória da aula do dia 05/03/2018. Ao fim da leitura, o professor retoma a palavra e pede se alguém da turma gostaria de acrescentar algo a mais no relato feito pelo referido educando. Nesse sentido, alguns educandos e algumas educandas acrescentaram mais relatos à mencionada memória. Em um segundo momento e como que para 
introduzir um dos temas/conceitos da aula de hojePesquisa Coletiva - o professor projeta perguntas ou comentários construídos por sete educandos (as) a respeito do artigo sobre pesquisa coletiva na formação de professores. Depois dessa projeção, alguns dos educandos fazem a leitura das suas observações sobre o citado artigo. Após essa leitura o professor retomou o diálogo perguntando se alguém têm mais alguma consideração a fazer a respeito do artigo em análise. Outros educandos emitem mais comentários com relação ao conteúdo acerca do emprego de metodologias participativas no campo da educação. No retorno do intervalo, o professor orientou que cada discente formulasse 3 perguntas sobre o que gostariam de estudar /pesquisar nessa disciplina. Logo após, enumerou cada aluno com um algarismo e, em seguida - a partir da identificação do algarismo dado aos educandos - foram formados 4 grupos com 4 componentes em cada um dos grupos. Ao término dessa tarefa, o professor pediu para que cada grupo escolhesse 3 perguntas, dentre as 12 perguntas construídas, para serem expostas no quadro. Aí então, com as perguntas elencadas no quadro, o professor pediu que cada um dos educandos elejam as 7 melhores perguntas atribuindo escores de notas nas escalas de 1 a 7 dentre essas 12 perguntas expostas no quadro. Por fim, um educando e uma educanda transcreveram em uma tabela as perguntas realizadas por todos os educandos com as suas respetivas notas.

Como se verifica pela citação, a construção da memória apresenta elementos muito importantes para a formação dos educandos da disciplina, que são professores e professoras em diversas instituições públicas e privadas do Brasil, no tocante a constituição desses professores e professoras como pessoas que buscam ensinar e aprender - de forma solidária com o outro - os conteúdos elencados e apresentados pelo grupo a partir das necessidades e dificuldades apresentadas por esses educandos.

A memória, nesse caso, é uma (re)criação do processo da caminhada pedagógica individual de cada componente da turma, bem como de uma escrita coletiva do grupo de educandos como um 
todo. Nesse relato desse fragmento de memória, verifica-se a emersão de uma situação pedagógica que proporciona vez e voz a todos os participantes da comunidade de aprendizagem em função de uma perspectiva, que proporciona a emersão do ser humano como um ser que dialoga com o outro em um quefazer consignado por uma educação estruturada em valores da liberdade, da reciprocidade e da alteridade, os quais são vivenciados tanto pelo docente como pelos discentes.

Essa situação emergiu da prática pedagógica alicerçada em valores consubstanciados no respeito à alteridade e no diálogo, que se configurou nos seguintes atos: sair de si e ao encontro do outro, colocar-se a partir do ponto de vista do outro, sentir a compaixão pelos outros e praticar a dádiva sem medida e espera de recompensa (MOUNIER, 2004).

Dessa feita, o docente assegura em conjunto com os educandos uma formação humana, amparada no congraçamento entre os indivíduos em que as práticas educativas são consignadas em preceitos sustentados por Freire (1967), que diz que a educação deve ser criada e recriada como prática de liberdade, em que todos partilharam os ensinamentos e as aprendizagens coletivamente, cujo núcleo fundante foi a prevalência da reciprocidade, presente na razão solidária, em contraposição ao individualismo característico da razão neoliberal.

Desse modo, o processo de formação dos educandos e do docente se deu em um movimento de disponibilidade entre os educandos (as) e o docente, cujos encontros se realizaram em um ambiente de uma atmosfera amistosa eu que o eu foi constituído pelo tu, assim como o tu foi constituído pelo eu, formando um nós comunitário, ou seja o eu se responsabilizou pelo tu e por sua vez, o tu se responsabilizou pelo eu em uma sucessão de atos de reconhecimento mútuo entre o eu e o tu, o qual promoveu efetiva a dialogicidade na relação entre os polos desses encontros (eu e tu), acarretando na prática a emersão de processos pedagógicos e políticos em que esses polos crescem mutuamente como pessoas, que: "não pode realizar-se no isolamento, no individualismo, mas na comunhão, na solidariedade dos existires, daí que seja impossível 
dar-se nas relações antagônicas entre opressores e oprimidos". (FREIRE, 2005, p.105).

Logo, emergiu e irrompeu pressupostos éticos que são fundamentados na transformação dos indivíduos fechados em si mesmos em pessoas disponíveis para os outros que emergem pelo amor. Assim sendo, a esfera intersubjetiva se estabeleceu pela confluência de interesses guiados pela máxima de Mauss (2008), que diz que a vida é um constante dar, receber e retribuir, cujo fim primeiro é a transformação do mundo social vigente, organizado na competitividade e no individualismo, em um mundo constituído por uma sociedade calcada na cooperação. Ou seja, num mundo erigido sob as bases de uma humanização plena, que - conforme Freire (1979) - se realiza pela vocação ontológica do ser mais com o outro. A respeito dessa vocação, esse autor esclarece que:

Sem dúvida, ninguém pode buscar na exclusividade individualmente. Esta busca solitária poderia traduzir-se em um ter mais, que é uma forma de ser menos. Esta busca deve ser feita com os outros seres que também procuram ser mais e em comunhão com outras consciências, caso contrário se faria de umas consciências, objetos de outras. Seria "coisificar" as consciências. Jaspers disse: "eu sou na medida em que os outros também são". O homem não é uma ilha. É comunicação. Logo, há uma estreita relação entre comunhão e busca. (FREIRE, 1979, p.28).

Seguindo nessa "trilha" apontada por Freire, no excerto acima, corroboramos com a ideia desse autor e observamos que as atividades realizadas na disciplina de Seminários Avançados imprimiu uma metodologia caracterizada por uma prática pautada e sustentada na ética da alteridade e do diálogo, pois a formação dos educandos e do docente se deu numa interação em torno do desenvolvimento das potencialidades de todas as pessoas - que participaram da referida disciplina -, cuja comunhão era incentivada e apoiada pelo docente e pelos discentes.

Nestes encontros, houve uma convergência entre o docente e os educandos em torno da colaboração entre esses na totalidade 
de suas alteridades, rompendo-se assim com o individualismo egoísta, esmagador do humano, ao instaurar a abertura amorosa ao outro como fundamento ético, estético e político de uma Pedagogia forjada na prática e no respeito à alteridade como condição primeira para a constituição do indivíduo como pessoa, de modo geral, e como docente de maneira particular.

Pedagogia esta que é pensada e vivida a partir do movimento dialógico em que há um reconhecimento e um respeito à alteridade de cada um dos sujeitos do quefazer pedagógico e político, possibilitando uma comunhão perfeita desses sujeitos em prol da transformação social. Nessa direção, Freire explicita de como ocorre essa comunhão:

O eu dialógico, pelo contrário, sabe que é exatamente o tu que o constitui. Sabe também que, constituído por um tu - um não-eu -, esse tu que o constitui se constitui, por sua vez, como eu, ao ter no seu um tu. Desta forma, o eu e o tu passam a ser, na dialética destas relações constitutivas, dois tu que se fazem dois eu. Não há, portanto, na teoria dialógica da ação, um sujeito que domina pela conquista e um objeto dominado. Em lugar disto, há sujeitos que se encontram para a pronúncia do mundo, para a sua transformação. (FREIRE, 2005, p.192).

Daí decorre que essa comunhão era vivida no cotidiano das aulas como uma ideia-força constituída pelo signo da alteridade em que o outro era acolhido em sua totalidade como um sujeito respeitado em sua dignidade como pessoa, a qual revela uma riqueza de saberes.

Essa riqueza de saberes serviu para um alargamento do horizonte de todos os participantes das aulas como sujeitos, em processo inconcluso e inacabado de formação, como seres humanos preocupados, conforme Milani (1967), mais com o ensinar e o aprender em coletividade em oposição as práticas de formação orientadas pela verticalidade e, como consequência, pelo antidiálogo. 
Diante desse panorama da formação docente, podemos vislumbrar processos sociais baseados numa metodologia de pesquisa coletiva como uma proposta para o desenvolvimento de uma prática pedagógica comprometida com a mudança da sociedade em que as relações sejam de colaboração entre os sujeitos sociais, cujo objetivo seja a reconstrução do conhecimento por intermédio de uma epistemologia subsidiada numa teoria do pensamento coletivo, que:

A fertilidade da teoria do pensamento coletivo se mostra precisamente na possibilidade que nos proporciona para comparar e investigar de forma uniforme o pensar primitivo, arcaico, ingênuo [...] também pode ser aplicado ao pensamento de um povo, de uma classe ou de um grupo [...]. (FLECK, 1986, p.96).

Teoria esta que pode suscitar e promover uma formação de professores como um alargamento das liberdades e da participação democrática desses professores em favor da emersão de um mundo fundado num desenvolvimento social sustentado por uma razão solidária, que se efetiva - conforme Mounier (1961) - através de uma educação que gera a transformação dos indivíduos em pessoas capazes de fazer a conversão da economia e da cultura do mercado para uma economia e uma cultura organizada por meio dos princípios garantidores das necessidades humanas individuais de cada um dos seres humanos e das necessidades do coletivo da comunidade de pessoas.

Esse desenvolvimento social tem sua contribuição dada pela pesquisa e pela prática política e pedagógica, cujo núcleo fundante é a educação dos futuros docentes com vistas à (re)construção de um currículo, por esses e pelos discentes, em torno da emergência de uma consciência social forjada no diálogo intercultural a partir do reconhecimento das diferenças de classes sociais, de gênero, etnia, sexo, religião, língua e nacionalidade, as quais são edificadas por meio da luta de educadores, educandos e movimentos e organizações sociais dentro de uma visão que une ação e reflexão da 
vida cotidiana desses atores como a constituição de um currículo: "como uma disputa de lugares". (ARROYO, 2013, p.368)

Lugares estes que são pensados e refletidos por intermédido de uma Pedagogia radical, que vislumbra os professores como intelectuais que se comprometem com a transformação social, cultural, política e econômica das escolas e de outros espaços da sociedades, a qual se dar por meio do diálogo comunitário entre os atores sociais numa perspectiva da emersão da solidariedade e da democracia em que a formação dos professores seja sustentada numa teoria pedagógica que leve em conta não somente os aspectos econômicos como determinantes das relações sociais, mas também os aspectos políticos, ideológicos, de gênero e sobretudo da cultura como uma matiz fundante para o entendimento da vida em sociedade. (GIROUX; MACLAREN, 2013). Ou seja, que seja instaurada uma Pedagogia que responda ao anseio de um viver alicerçado na cooperação.

\section{CONSIDERAÇÕES FINAIS}

De maneira oposta a uma formação docente forjada na criticidade e na emancipação humana, percebe-se hegemonicamente - um pensamento e uma prática de professores sustentados em epistemologias que apontam para o emprego de metodologias calcadas no anti-diálogo e muita das vezes desconectadas da nossa realidade latino-americana

Assim sendo, no Brasil, a formação de professores acaba sendo desconectada do pensamento crítico originário do continente latino-americano pelo fato de que os centros de formação desse país, em grande parte, fundamentam suas pesquisas em autores pertencentes aos países do norte global, no que se refere à produção do conhecimento a ser comunicado aos docentes. Há, nesse caso, a veiculação por por esses centros de um pensamento de matriz colonial, o qual limita a emersão de uma formação docente estruturada numa visão de uma educação produzida a partir da realidade do nosso povo e para o nosso povo, ou seja, de uma educação praticada com base nos pilares da autonomia, da libertação, do diálogo e da alteridade. 
Como possibilidade a esse tipo de formação, que converge com pedagogias insurgentes, imaginamos que 0 trabalho cooperativo em torno do aprofundamento de práticas coletivas na educação do professor e dos futuros professores, que se estrutura a partir de uma ação que vai das concepções e leituras individuais e suas socializações com o grupo e ainda com os dados que são colocados por cada participante para formar a pesquisa de cunho coletivo, podem gerar caminhos que devem levar ao surgimento de processos de ensino e de aprendizagem, que imprimam a dialogicidade e o reconhecimento da alteridade como categorias indispensáveis para a realização da tarefa docente, imersa na realidade social.

Na nossa visão, entendemos que essa pedagogia deve ser construída a partir da denúncia de uma formação de professores sustentada pela lógica do capital, hegemônica competitiva e individualista, presente no mundo atual, concomitante com o anúncio e a efetivação de uma formação permanente de professores forjada na cooperação entre as pessoas, cuja finalidade seja a implantação de um mundo social onde caibam todas as pessoas, isto é, de um mundo em que a educação ajude na construção de sociedades mais amorosas e solidárias.

Sendo assim, entendemos que um pensamento apoiado em uma teoria e uma prática de formação docente forjada no coletivo pode permitir um (re)fazer pedagógico capaz de ajudar na transformação da sociedade vigente, hegemonicamente forjada na ética de mercado, em uma sociedade em que a cooperação seja a tônica dos sentimentos e das ações cotidianas, assim como foi experimentada essa cooperação na disciplina de seminários avançados de modo 'sentipensante', ao unir as emoções provenientes do coração e da razão originária da mente, seguindo o ideário de Fals Borda (2009), que atuava e lutava em favor de uma transformação social e de um pensamento autônomo, crítico e o originário do nosso continente latino-americano.

Portanto, a formação de professores deve se orientar por uma teoria e uma prática comprometidas com a (re)construção de um mundo com base na civilização cooperativa que se faz, a nosso ver, por meio de processos pedagógicos e políticos - no ambiente das 
escolas, das outras organizações sociais - sustentados numa construção coletiva de todos os sujeitos sociais em prol da constituição do "bem viver" sustentado nos princípios da solidariedade, integralidade, responsabilidade e convivialidade entre todas pessoas com vistas a uma vida forjada na convergência da estética e ética comunitária, as quais são criadas e recriadas na colaboração entre os sujeitos sociais em que a política, a economia, a ideologia e sobretudo a cultura têm um papel imprescindível na educação dos educandos(as) professores(as).

Enfim, que a cultura tenha um papel decisivo na constituição de educandos e educandas como um fator que consiste: "no modo particular de organizar as práticas humanas como uma experiência coletiva, abarcando um sistema de símbolos que conferem significado à experiência." Pacheco (2005, p.68). Portanto, que o coletivo seja o ponto de partida e de chegada dos processos pedagógicos e políticos da formação dos futuros e dos atuais educadores com a finalidade de forjar o mundo centrado na cooperação em substituição ao mundo atual dominado pela competitividade.

\section{REFERÊNCIAS}

ARROYO, M. G. Currículo, território em disputa. Petropólis: Vozes, 2013.

ARRUDA, M. Educação para uma economia do amor: Educação da práxis e economia solidária. Aparecida: Ideias \& Letras, 2003.

$\mathrm{BLOCH}, \mathrm{E}$. O Princípio esperança. Rio de Janeiro: Contraponto/Ed UERJ,2005.

BRANDÃO, C. R. Aprender o amor: um afeto que se aprende a viver. Campinas: Papirus, 2005.

BUBER, M. Eu e Tu. São Paulo: Centauro, 2001.

DALLA ROSA, L. C. Educar para a sabedoria do amor: A epifania do rosto do outro como uma pedagogia do êxodo. Tese ao 
Programa de Pós-graduação em Teologia da Escola Superior de Teologia. São Leopoldo, EST, 2010.

DARDOT, P.; LAVAL, C. A nova razão do mundo: ensaio sobre a sociedade neoliberal. São Paulo: Boitempo Editorial, 2016.

FALS BORDA, O. Uma sociologia sentipensante para América Latina. Bogotá: Siglo del Hombre Editores y Clacso,2009.

FIGUEIREDO, J.; FRANTZ, W. (re)construir a escola e a sociedade a partir da epistemologia de Paulo Freire. Reflexão e Ação, Santa Cruz do Sul, v. 26, n. 1, abr. 2018.

FLECK, L. La Génesis y el Desarrollo de un Hecho Científico. Madrid: Alianza Editorial, 1986

FREIRE, P. Educação como prática de liberdade. Rio de Janeiro: Paz e Terra, 1967.

FREIRE, P. Educação e mudança. Rio de Janeiro: Paz e Terra, 1979.

FREIRE, P. Pedagogia do Oprimido. Rio de Janeiro: Paz e Terra, 2005.

GIROUX, H.; MACLAREN, P. Formação do professor como uma contra-esfera pública: a Pedagogia radical como uma forma de política cultural. In: MOREIRA, A. F.; DA SILVA, T. T. (Orgs.). Currículo, cultura e sociedade. São Paulo: Cortez, 2009.

LABOV, W. Sociolinguistic patterns. Philadelphia: University of Pensylvania Press, 1972.

LÉVINAS, E. Totalidade e infinito. Lisboa: Edições 70, 2000.

MARQUES, M. O. A Aprendizagem na Mediação Social do Aprendido e da Docência. ljuí: Editora UNIJUI, 1998.

MAUSS, M. Ensaio sobre a Dádiva. Lisboa: Edições 70, 2008.

MBEMBE, A. Necropolítica. São Paulo: $n-1$ edições, 2018.

MILANI, L. SCUOLA DI BARBIANA. Lettere a uma professoressa.

Firenze: Libreria Editrice Fiorentina, 1967.

MOUNIER, E. Manifeste au service Du personnalisme. Ouevres. T.1. Paris: Le Seuil, 1961 
MOUNIER, E. O personalismo. São Paulo: Centauro, 2004.

PACHECO, J. P. Escritos curriculares. São Paulo: Cortez, 2005.

TOMASSELO, M. ¿Por qué cooperamos?. Madrid: Katz Editores, 2010.

Submetido em: Maio/ 2020.

Aceito em: Fevereiro/ 2021. 